\title{
New Patterns of Temporal and Spatial Variation in Water Quality of a Highly Artificialized Urban River-Course-A Case Study in the Tongzhou Section of the Beiyun River
}

\author{
Juanhui Ren ${ }^{1}$, Ji Liang ${ }^{2, *}$, Bo Ren ${ }^{2,3}$, Xiuqing Zheng ${ }^{1, *}$ and Chaofan Guo ${ }^{4}$ \\ 1 College of Water Resources Science and Engineering, Taiyuan University of Technology, \\ Taiyuan 030024, China; chunyanxueyan@163.com \\ 2 College of Hydropower and information Engineering, Huazhong University of Science and Technology, \\ Wuhan 430074, China; 15803437755@163.com \\ 3 Hydrology Bureau of Shanxi Province, Taiyuan 030001, China \\ 4 College of Natural Resources and Environment and Tourism, Beijing Normal University, \\ Beijing 010000, China; yhydyjy@163.com \\ * Correspondence: larkwater1@163.com (J.L.); zhengxiuqing@tyut.edu.cn (X.Z.); \\ Tel.: +86-132-9700-9229 (J.L.); Tel.: +86-351-601-0102 (X.Z.)
}

Received: 17 July 2018; Accepted: 11 October 2018; Published: 13 October 2018

check for updates

\begin{abstract}
This paper aims to gain a better understanding of urban river pollution through evaluation of water quality. Data for 10 parameters at eight sites of the Tongzhou Section of the Beiyun River (TSBR) are analyzed. Hierarchical cluster analysis, fuzzy comprehensive assessment, discriminant analysis and Spearman's correlation analysis were used to estimate the water situation of each cluster and analyze its spatial-temporal variations. Principal component analysis/factor analysis were applied to extract and recognize the sources responsible for water-quality variations. The results showed that temporal variation is greater than spatial and sewage discharge is the dominant factor of the seasonal distribution. Moreover, during the rapid-flow period, water quality is polluted by a combination of organic matter, phosphorus, bio-chemical pollutants and nitrogen; during the gentle-flow period, water quality is influenced by domestic and industrial waste, the activities of algae, aquatic plants and phosphorus pollution. In regard to future improvement of water quality in TSBR, the control of reclaimed wastewater from adjacent factories should first be put in place, as well as other techniques, for example, an increase of the impervious area, low-impact development, and integrated management practices should also be proposed in managing storm water runoff.
\end{abstract}

Keywords: Tongzhou Section of the Beiyun River; multivariate statistical analysis; fuzzy comprehensive assessment; urban river-course; spatial and temporal variations

\section{Introduction}

Services provided by river-course ecological systems, such as rivers and lakes, contribute to water habitat and human welfare directly and indirectly [1]. Rivers play an important role in assimilating and carrying point source pollution (mainly from domestic and industrial wastewater) and non-point source pollution (runoff from agricultural land) [2-5]. As the most vulnerable water bodies to pollution, it is imperative to recognize river water quality and interpret spatial and temporal variation patterns [6-9]. For over a century, large scales of modern engineering technologies have been employed in river renovation. Until now, about $60 \%$ of rivers around the world have gone through artificialization such as damming, banking and channelization to meet human needs [10]. This may result in a different 
hydrological and hydro-chemical characteristic when compared to natural river courses. Studies on pollution status and distribution in urban river courses may serve as a guidance for water quality improvement and water safety insurance in urban areas.

Spatial and temporal variations of river water condition have always been a hotspot for research on water environments. While most studies focus on natural river courses or lakes, there is still lack of research on highly artificialized urban river courses, which always occur on a small scale. V. Simeonov et al. focus on a three-year survey conducted in the major river systems (Aliakmon, Axios, Gallikos, Loudias and Strymon) as well as streams, tributaries and ditches in Northern Greece, using a multivariate receptor model to estimate the contribution of identified sources to the concentration of the physicochemical parameters [6]. Research on marine water quality in Eastern Hong Kong found that water quality in 12 months could be grouped into two groups, June-September and the remaining months, and the entire area could be divided into two parts, representing different pollution levels. Pattern recognition provided better information for Hong Kong offshore water-quality monitoring and function division, in the meantime allowed the identification of possible factors that influenced the water systems [10]. Pejman et al. [11] used multivariate statistical techniques to evaluate spatial and seasonal variations of water quality in the Haraz River Basin, providing a representative and reliable estimation to get more information about water quality and design monitoring network.

Multivariate mathematical and statistical techniques serve as useful tools in river water-quality assessment and feature recognition [12-15]. Due to the complication of evaluation indicators in river water, the assessment results obtained from only one parameter may easily mislead or bias the user; therefore, fuzzy comprehensive assessment (FCA) plays a significant role in water quality assessment [16-18]. In addition, multivariate statistical methods have been widely applied to characterize and evaluate freshwater, groundwater and seawater in the last 10 decades [19]. According to previous research, multivariate statistical methods, such as cluster analysis (CA), discriminant analysis (DA), principal component analysis/factor analysis (PCA/FA) proved helpful in extracting significant information from complicated dataset, as well as identifying major source which have great impact on water quality to help gain a good knowledge of ecosystem and water quality conditions within study areas [20-24].

Considering the above considerations, the paper first presents a description of monitoring water parameters of the Tongzhou Section of the Beiyun River (TSBR) in 2014 and 2015, to gain a sketchy understanding of urban river course water conditions. Then a combination of Spearman's correlation analysis and discriminate analysis was performed for a discrimination of water environment factors that are vulnerable for the spatial and temporal variation of water pollution. The results, which box and whisker plots showed, combined with FCA, could be of great help in understanding the spatial and temporal variation of water quality. Finally, PCA/FA was used for source apportioning in each period, combining on-site investigation. The paper also explores the origin of different sources and pollution variation between two periods. The results of present study may serve as guidance for optimizing networks, screening monitoring indicators, and providing theoretical basis for future river restoration projects.

\section{Materials and Methods}

\subsection{Study Areas}

Beiyun River is the main branch of the Hai River. Upstream of the Beiyun River (viz. Wenyu River) has a length of $47.5 \mathrm{~km}$ and a catchment area of $2403 \mathrm{~km}^{2}$. Downstream of the Beiyun River has a length of $41.9 \mathrm{~km}$ and catchment area of $1945 \mathrm{~km}^{2}$. The climate belongs to continental monsoon climate zone, with a mean annual precipitation of $620 \mathrm{~mm}$, and average temperature of $11.3{ }^{\circ} \mathrm{C}$. May-September is the rainy season, accounting for $85 \%$ of total precipitation of the year. Average evaporation of the surface water is between $400-500 \mathrm{~mm}$. The study area has undergone a sharp reduction of precipitation in recent years. 


\subsection{Sampling and Parameters}

Water samples were collected from eight sites along the main channel of the Beiyun River in Spring (March, April, May), Summer (June, July, August), and Autumn (October) of 2014 and 2015 (Figure 1). Duplicate water samples were collected with a plastic container at each selected sampling site. The samples were placed in $1000 \mathrm{~mL}$ plastic bottles that had been soaked in dilute nitric acid for $24 \mathrm{~h}$, and rinsed thoroughly with deionized water. These samples were taken to the laboratory and stored in a refrigerator at $-4{ }^{\circ} \mathrm{C}$ for further analysis.

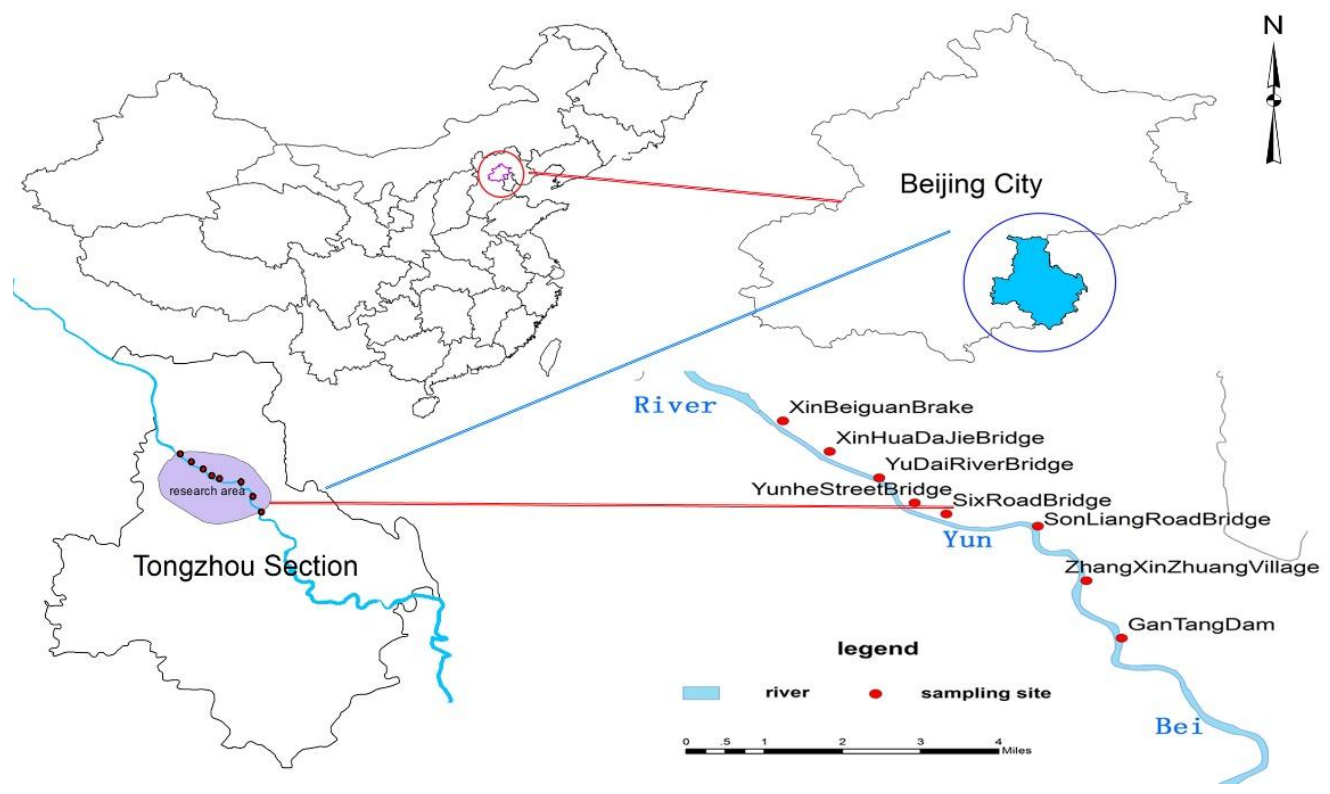

Figure 1. Map of the study area and surface water sampling sites in the Tongzhou Section of the Beiyun River (TSBR).

Ten parameters were measured including $\mathrm{DO}, \mathrm{Chl}-a, \mathrm{SS}, \mathrm{TN}, \mathrm{NH}_{4}-\mathrm{N}, \mathrm{NO}_{3}-\mathrm{N}, \mathrm{COD}, \mathrm{BOD}_{5}$, TP, $\mathrm{PO}_{4}$-P. Among them, DO, Chl- $a$, SS were measured on-site by Hydrolab Datasonde5. TN was determined using Multi N/C UV, and $\mathrm{PO}_{4}-\mathrm{P}$ was determined by using ammonium molybdate tetrahydrate spectrophotometry. Other determinations measurements were based on the "Environmental Quality Standards for Surface Water" of China (GB 3838-2002).

\subsection{Analytical Methods}

\subsubsection{Fuzzy Comprehensive Assessment (FCA)}

For water quality assessment, single index/parameter may not be enough in illustrating water conditions, and FCA emerged to overcome the disadvantages of the single index method. Fuzzy evaluation methods comprehensively evaluate the contributions of various pollutants according to predetermined weights, and decrease the fuzziness by using membership functions. Therefore, the sensitivity is quite high compared to other index evaluation techniques [25]. FCA has proved effective in solving problems of fuzzy boundaries and in controlling the effect of monitoring errors on assessment results [26-28].

\subsubsection{Multivariate Statistical Methods}

Hierarchical cluster analysis (HCA), discriminant analysis (DA) and principal component analysis/factor analysis (PCA/FA) have been applied on the standardized data set of surface water quality in TSBR. All the calculations are implemented by Office Excel 2010 (Microsoft Corporation 
of Washington, USA) and SPSS 21.0 (Norman H. Nie, C. Hadlai (Tex) Hull, and Dale H. Bent, the Headquartered is in Chicago, USA.).

HCA, the most widely used, is an exploration method developing from CA. Its primary function is to assemble objects based on characteristics' closeness. Based on their similarity, objects are clustered step by step until only one cluster remains [29]. The similarity can be expressed in two ways: distance between samples or classes [30]. In this paper, HCA is used to interpret the data and indicate patterns [3]. Ward's method with squared Euclidean distances is used for similarity measurement. The results are typically illustrated by a dendrogram (tree diagram), which provide a visual summary of the clustering processes [31,32]. DA is used to confirm the cluster found by HCA, while at the same time determining the most significant parameters responsible for spatial and temporal variations. Standard and stepwise modes of DA have been used in this paper. The clusters which HCA show is the grouping variables, and the measured parameters are the independent variables; the accuracy of DA results is tested by cross-validation.

PCA is a pattern recognition technique that attempts to explain the variance of a large set of inter-correlated variables by transforming them into a smaller set of independent variables [2,6]. PCA is executed to extract significant principal components (PCs), then FA further reduces the contribution of less significant variables obtained from PCA and the new group of variables known as variance factors (VFs) is extracted through rotating the axis defined by PCA. A VF can include unobservable, hypothetical, and latent variables, while a PC is a linear combination of observable water-quality variables $[3,24]$. When applies to water quality analysis, it is mainly used to extract pollution factors and recognize pollution sources [33].

\section{Data Analysis and Results}

\subsection{The Overall Status of Water-Quality Characteristics}

Summary characteristic of each parameter and guideline of national standards for surface water are shown in Table 1. By comparison between each parameter's mean value and associated national standard, it can be seen that the whole water quality in TSBR is poor. Seven out of 10 parameters are beyond the national standard $\mathrm{V}$. N and P pollutions are the most severe. The mean value of TN reaches $22.25 \mathrm{mg} \cdot \mathrm{L}^{-1}$, five times higher than standard $\mathrm{V}$. TP is four times higher with an average of $1.85 \mathrm{mg} \cdot \mathrm{L}^{-1}$. In view of variable coefficients, Chl- $a(139.15 \%)$ and DO $(103.33 \%)$ rank the top, followed by $\mathrm{NO}_{3}-\mathrm{N}(65.22 \%), \mathrm{SS}(56.30 \%), \mathrm{BOD}_{5}(47.65 \%)$, which means a higher degree of dispersion and an uneven distribution in different periods and sites among these parameters. Similar situations were also found in other studies, which showed a poor water quality in urban areas. For example, Surindra [34] suggested that ranges of key water quality parameters such as, DO, BOD, COD and TDS, were several times higher than the prescribed standards, and that urban runoff and industrial wastewater discharges were the major threats to river water quality at Ghaziabad. Overall, the water quality of Hindon was relatively poor with respect to its use for domestic purposes. Alam, Hossain and Khan's [35] study on deterioration of water quality of the Surma River indicated that the water of the Surma River was polluted from various sources like sewage and garbage disposal. The river was found to be highly turbid in the monsoon season. Concentration of BOD and fecal coliform was found to be higher in the dry season. The water was unfit for drinking purposes without any form of treatment, but for various purposes of other surface water usage, it still could be considered quite acceptable. 
Table 1. Statistics of measured parameters and the national standards for surface water quality.

\begin{tabular}{|c|c|c|c|c|c|c|c|c|c|c|c|}
\hline \multicolumn{7}{|c|}{ Summary Statistics of Measured Parameters } & \multicolumn{5}{|c|}{ National Standards for Surface Water Quality } \\
\hline $\mathrm{NH}_{4}-\mathrm{N}$ & $\mathrm{mg} / \mathrm{L}$ & 0.30 & 22.76 & 11.53 & 4.59 & 39.83 & 0.15 & 0.50 & 1.00 & 1.50 & 2.00 \\
\hline $\mathrm{TP}$ & $\mathrm{mg} / \mathrm{L}$ & 0.57 & 5.64 & 1.85 & 0.64 & 34.53 & 0.02 & 0.10 & 0.20 & 0.30 & 0.40 \\
\hline $\mathrm{PO}_{4}-\mathrm{P}$ & $\mathrm{mg} / \mathrm{L}$ & 0.44 & 3.31 & 1.48 & 0.52 & 35.43 & - & - & - & - & - \\
\hline COD & $\mathrm{mg} / \mathrm{L}$ & 2.30 & 132.00 & 57.75 & 19.57 & 33.89 & 15.00 & 15.00 & 20.00 & 30.00 & 40.00 \\
\hline Chl-a & ug/L & 4.09 & 955.06 & 96.82 & 134.72 & 139.15 & - & - & - & - & - \\
\hline SS & $\mathrm{g} / \mathrm{L}$ & 5.00 & 66.00 & 15.71 & 8.84 & 56.30 & 15.00 & 15.00 & 20.00 & 30.00 & 40.00 \\
\hline DO & $\mathrm{mg} / \mathrm{L}$ & 0.06 & 15.40 & 3.85 & 3.98 & 103.33 & 7.50 & 6.00 & 5.00 & 3.00 & 2.00 \\
\hline
\end{tabular}

\subsection{Temporal and Spatial Distribution Characteristics of Water Quality}

HCA assembles the objects into different clusters based on their similarity, and is used for recognizing the temporal and spatial distribution recognition. Then, standard and stepwise modes of DA are used to confirm the cluster found by HCA and to determine the most significant parameters determining spatial and temporal variations. In combination with the DA and Spearman's correlation analysis, the temporal and spatial distribution characteristics of water environmental element can be obtained.

\subsubsection{Temporal Variations}

Both of seasons and points are non-numeric parameters, so an assignment is necessary before the statistical analysis. The dendrogram of temporal HCA is shown in Figure $2 \mathrm{a}$. It is observed that all the monitoring months can be obviously classified into two statistically meaningful clusters at $\left(\mathrm{D}_{\text {link }} / \mathrm{D}_{\max }\right)^{*} 100<15$ (the quotient between the linkage distance for a particular case divided by the maximal distance). Cluster 1 contains May-October, and Cluster 2 contains March-April. As indicated before, $85 \%$ of the precipitation is concentrated in May-September; therefore, Cluster 1 and 2 basically correspond to the rapid-flow period and gentle-flow period, respectively.
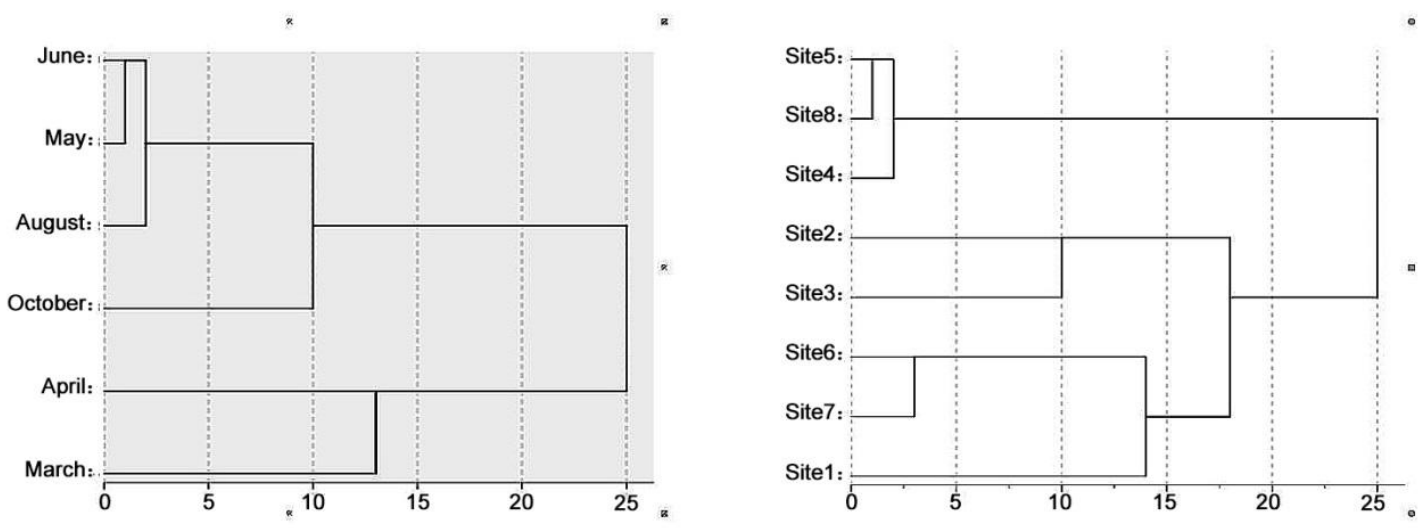

Figure 2. Dendrogram of cluster analysis for spatial and temporal variation in TSBR. (a) Temporal cluster analysis. (b) Spatial cluster analysis.

Integrated evaluation of water quality can be derived through FCA, which demonstrates in Table 2 that water quality are both beyond level $\mathrm{V}$ in the selected two periods. The results are largely affected by TN and TP's heavy weighting, which means severe $\mathrm{N}$ and P pollution in TSBR. By comparison between the pollution levels between two periods, it is observed that the pollution level in the rapid-flow period (0.976) is higher than gentle-flow period (0.942), which reveals the scouring movement by rainfall in the rapid-flow period. In addition, runoff carries large amounts of land and atmosphere pollutants into the river-course, so non-point source pollution becomes more serious [36]. On the other hand, due to the 
runoff erosion, endogenous load within the river course (which is mainly from point source pollutants) can be released, which in turn increases pollutant concentration in rapid-flow period [37-39].

Table 2. Integrated evaluation form of water quality.

\begin{tabular}{ccccccc}
\hline & Scales & I & II & III & IV & V \\
\hline \multirow{2}{*}{ Temporal } & Gentle-flow (GF) period & 0.000 & 0.000 & 0.007 & 0.061 & 0.942 \\
& Rapid-flow (RF) period & 0.000 & 0.011 & 0.003 & 0.009 & 0.976 \\
\hline \multirow{3}{*}{ Spatial } & Upstream & 0.000 & 0.002 & 0.018 & 0.000 & 0.982 \\
& Middle-stream & 0.003 & 0.003 & 0.000 & 0.021 & 0.969 \\
& Downstream & 0.000 & 0.000 & 0.020 & 0.029 & 0.960 \\
\hline
\end{tabular}

Tables 3 and 4 show classification functions and verification obtained from the standard, stepwise modes of DA. For temporal DA, standard mode assigning 97.8\% of cases means the selected 10 parameters can explain temporal variation of water quality successfully. While for stepwise mode, correct assignations reach $93.3 \%$ using only three parameters, which means $\mathrm{Chl}-\mathrm{a}, \mathrm{TN}, \mathrm{PO}_{4}-\mathrm{P}$ should be enough to illustrate temporal variation. This suggests that the monitoring intensity of these three parameters should be appropriately increased in future works.

The results of SCA are shown in Table 5. $\mathrm{NH}_{4}-\mathrm{N}, \mathrm{TN}, \mathrm{TP}, \mathrm{PO}_{4}-\mathrm{P}, \mathrm{BOD}_{5}, \mathrm{Chl}-\mathrm{a}$ are found significantly (sig. < 0.01) correlated with the periods, suggesting that these parameters can be easily affected by temporal factors like water stage or flow rate. Through the results from SCA and DA, three parameters selected by SCA cannot be found through DA. $\mathrm{NH}_{4}-\mathrm{N}, \mathrm{TP}, \mathrm{BOD}_{5}$ which correlates with the periods. The temporal variation is explained by. $\mathrm{NH}_{4}-\mathrm{N}, \mathrm{TP}$, whose loss of discriminant ability is mainly caused by flexible water discharge from factories along the main river course in Tongzhou section. In addition, the degradation ability of microbial factors varies along with the scale and frequency of the water discharge, which explains $\mathrm{BOD}_{5}$ fails to show seasonal variations. The results also suggest that $\mathrm{NH}_{4}-\mathrm{N}, \mathrm{TP}, \mathrm{BOD}_{5}$ are highly vulnerable to human activities.

As identified by DA, box and whisker plots of the selected parameters showing temporal trends are demonstrated in Figure 3. Significant change occurs in all the 3 parameters. $\mathrm{NH}_{4}-\mathrm{N}_{\text {varies from } 3.14}$ to $19.20 \mathrm{mg} / \mathrm{L}$ in the rapid-flow period and $1.87-16.30 \mathrm{mg} / \mathrm{L}$ in the gentle-flow period. Average value in the gentle-flow period $(11.31 \mathrm{mg} / \mathrm{L})$ is higher than that in the rapid-flow period $(7.56 \mathrm{mg} / \mathrm{L}), \mathrm{which}$ can be explained as in the gentle-flow period. The microbial degradation rate of nitrogen is limited by the lower temperature. TP varies from 0.71 to $2.87 \mathrm{mg} / \mathrm{L}$ in the rapid-flow period and $0.57-1.63 \mathrm{mg} / \mathrm{L}$ in the gentle-flow period. Average value in the rapid-flow period $(1.69 \mathrm{mg} / \mathrm{L})$ is higher than that in the gentle-flow period (1.15 mg/L). Different kinds of non-point source pollution (including phosphorous pollutant) flow into the river course along with rainfall runoff in the rapid-flow period, and a higher temperature in the rapid-flow period may enhance the sediment phosphorus release [40]. For BOD the average value in the gentle-flow period $(12.14 \mathrm{mg} / \mathrm{L})$ is higher than that in the rapid-flow period $(7.60 \mathrm{mg} / \mathrm{L})$. Studies have shown a significant correlation between $\mathrm{BOD}_{5}$ and Chl-a. While BOD 5 peaks, algal blooms at the greatest level at the same time. Scarce water volume, insufficient water power, and higher nutrient concentrations can all enhance the respiration of phytoplankton, finally resulting in higher $\mathrm{BOD}_{5}$ in the gentle-flow period. 
Table 3. Classification functions for discriminant analysis (DA) of temporal and spatial variations.

\begin{tabular}{|c|c|c|c|c|c|c|c|c|c|c|c|c|c|}
\hline \multirow[b]{3}{*}{ parameters } & \multicolumn{4}{|c|}{ Temporal Discriminant } & \multicolumn{9}{|c|}{ Spatial Discriminant } \\
\hline & \multicolumn{2}{|c|}{ Standard Mode } & \multicolumn{2}{|c|}{ Stepwise Mode } & \multicolumn{3}{|c|}{ Standard Mode } & \multicolumn{3}{|c|}{ Stepwise Mode } & \multicolumn{3}{|c|}{ Stepwise Mode $(\mathrm{F}=2)$} \\
\hline & RF & GF & $\mathrm{RF}$ & GF & US & MS & DS & US & MS & DS & US & MS & DS \\
\hline Chl-a & 0.137 & 0.073 & 0.077 & 0.042 & 0.054 & 0.047 & 0.031 & & & & 0.028 & 0.009 & 0.017 \\
\hline $\mathrm{NH}_{4}-\mathrm{N}$ & 2.036 & 1.39 & & & 0.769 & 0.545 & 0.374 & & & & & & \\
\hline $\mathrm{NO}_{3}-\mathrm{N}$ & 3.089 & 2.227 & & & 1.231 & 1.569 & 1.078 & 0.394 & 0.32 & 0.714 & -0.023 & -0.234 & 0.301 \\
\hline $\mathrm{TN}$ & 1.026 & 0.558 & 1.417 & 0.772 & 0.232 & 0.279 & 0.515 & & & & 0.662 & 0.864 & 0.651 \\
\hline $\mathrm{TP}$ & 9.637 & 11.418 & & & 18.932 & 22.934 & 19.113 & & & & & & \\
\hline $\mathrm{PO}_{4}-\mathrm{P}$ & -16.826 & -6.4 & -1.011 & 8.095 & -5.002 & -9.721 & -6.828 & & & & & & \\
\hline COD & 1.323 & 1.105 & & & 1.044 & 1.183 & 1.094 & & & & & & \\
\hline $\mathrm{BOD}_{5}$ & -0.113 & -0.295 & & & -0.376 & -0.351 & -0.249 & & & & & & \\
\hline SS & 0.458 & 0.351 & & & 0.353 & 0.423 & 0.447 & & & & & & \\
\hline DO & -0.253 & 0.254 & & & 0.648 & 0.606 & 0.518 & & & & & & \\
\hline Residual & -80.929 & -54.933 & -21.26 & -14.327 & -52.81 & -62.798 & -55.323 & -2.26 & -1.867 & -4.911 & -8.446 & -9.645 & -10.018 \\
\hline
\end{tabular}

${ }^{3}$ RF/GF stand for rapid-flow period/gentle-flow period, US/MS/DS stand for up-stream/middle-stream/down-stream above. 
Table 4. Verification and classification functions for DA of temporal variations.

\begin{tabular}{ccccc}
\hline \multirow{2}{*}{ Discriminant Mode } & Period & Correct $\%$ & \multicolumn{2}{c}{ Period Assigned by DA } \\
\cline { 4 - 5 } & & & GF & RF \\
\hline \multirow{3}{*}{ standard mode } & GF & 93.3 & 14 & 1 \\
& RF & 100 & 0 & 30 \\
& Total & 97.8 & 14 & 31 \\
\hline \multirow{3}{*}{ stepwise mode } & GF & 93.3 & 14 & 1 \\
& RF & 93.3 & 2 & 28 \\
& Total & 93.3 & 16 & 29 \\
\hline
\end{tabular}

Table 5. Correlation coefficient of Spearman's correlation analysis for water quality.

\begin{tabular}{ccccccccccc}
\hline \multicolumn{10}{c}{ Spearman's Correlation Coefficient } \\
\hline & $\mathbf{N H}_{\mathbf{4}}-\mathbf{N}$ & $\mathbf{N O}_{\mathbf{3}}-\mathbf{N}$ & $\mathbf{T N}$ & $\mathbf{T P}$ & $\mathbf{P O}_{\mathbf{4}}-\mathbf{P}$ & $\mathbf{C O D}$ & $\mathbf{B O D}_{\mathbf{5}}$ & $\mathbf{C h l - a}$ & $\mathbf{S S}$ & DO \\
\hline Temporal & -0.402 & -0.009 & -0.513 & 0.515 & 0.677 & -0.201 & -0.412 & -0.438 & -0.207 & -0.018 \\
Sig. & 0.001 & 0.944 & 0.000 & 0.000 & 0.000 & 0.124 & 0.001 & 0.001 & 0.172 & 0.906 \\
Spatial & -0.103 & 0.337 & 0.214 & 0.188 & 0.092 & -0.047 & -0.024 & -0.107 & -0.064 & -0.297 \\
Sig. & 0.433 & 0.009 & 0.101 & 0.151 & 0.524 & 0.724 & 0.854 & 0.444 & 0.675 & 0.047 \\
\hline
\end{tabular}

${ }^{5}$ Sig. $<0.01$ correspond to extremely significant of correlation, Sig. $<0.05$ correspond to significant of correlation.
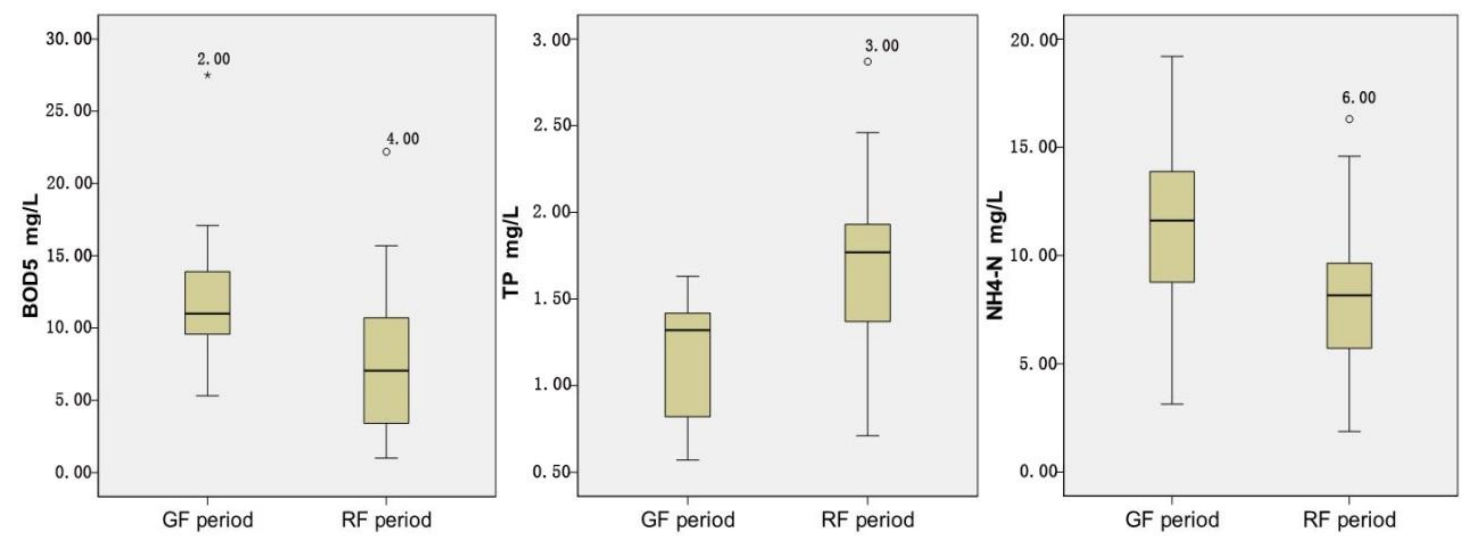

Figure 3. The trend of temporal variations of significant water quality parameters in TSBR.

Affected by natural conditions and human activities, the variation of water quality in urban river courses may have a unique pattern of temporal variation; this paper shows that different study objects may lead to different seasonal variation ranges. Pejman [11] indicated that the natural parameters (temperature and discharge), the inorganic parameter (total solid) and the organic nutrients (nitrate) were the most significant parameters contributing to water-quality variations for all seasons. Prakash Raj Kannel's partition was based on precipitation duration (pre-monsoon season and post-monsoon seasons), high level of $\mathrm{BOD}_{5}, \mathrm{COD}$ and low $\mathrm{DO}$ indicated that the level of organics was higher in the pre-monsoon season, while during post-monsoon season, the main pollutants were nutrients [41].

\subsubsection{Spatial Variations}

The dendrogram of spatial HCA is shown in Figure $2 b$; eight sampling stations can be grouped into three statistically meaningful clusters at $\left(D_{\text {link }} / D_{\max }\right)^{*} 100<18$. From the site location and distribution of supplement sites in Figure 1, these three clusters correspond to up-, middle and down stream of the reach which is filled with reclaimed water. Three sites from Cluster 1 (site 1, site 6 and site 7) comprise the closer sites to drainage channels. Cluster 2 (site 2 and site 3 ) corresponds to moderate distance sites. Cluster 3 (site 4 , site 5 and site 8 ) makes up the farthest ones. 
Spatial FCA is shown in Table 2, upstream of the reach has the largest membership degree to level $\mathrm{V}(0.982)$, followed by middle-stream (0.969) and downstream (0.960). The results show that water pollution has a slightly decrease trend when it travels from the upper stream to downstream.

As shown in Table 6, standard mode DA yields 64.4\% accuracy, which means spatial variation exists in TSBR, but is not as obvious as the temporal variation. Only one parameter $\left(\mathrm{NO}_{3}-\mathrm{N}\right)$ is selected by stepwise DA with the accuracy of less than $52.0 \%$, which indicates the fact that only one parameter cannot be enough in describing spatial variation of water quality. Therefore, the " $\mathrm{F}$ " value is changed to improve the determination accuracy. With " $\mathrm{F}=2$ " in the arithmetic [42], three parameters are identified, and the determination accuracy rises to $64.2 \%(69.6 \%, 64.3 \%$ and $56.3 \%$ for up, middle and downstream, respectively).

Table 6. Verification and classification functions for DA of spatial variations.

\begin{tabular}{cccccc}
\hline \multirow{2}{*}{ Discriminant Mode } & Part & Correct $\%$ & \multicolumn{3}{c}{ Part Assigned by DA } \\
\cline { 4 - 6 } & & & US & MS & DS \\
\hline \multirow{3}{*}{ Standard mode } & US & 73.7 & 14 & 2 & 3 \\
& MS & 53.8 & 1 & 7 & 5 \\
& DS & 61.5 & 4 & 1 & 8 \\
& Total & 64.4 & 19 & 10 & 16 \\
\hline \multirow{3}{*}{ Stepwise mode } & US & 50 & 12 & 5 & 7 \\
& MS & 72.2 & 2 & 13 & 3 \\
& DS & 33.3 & 4 & 8 & 6 \\
& Total & 51.7 & 18 & 26 & 16 \\
\hline \multirow{3}{*}{ Stepwise mode } & US & 69.6 & 16 & 3 & 4 \\
(F=2) & MS & 64.3 & 1 & 9 & 4 \\
& DS & 56.3 & 2 & 5 & 9 \\
& Total & 64.2 & 19 & 17 & 17 \\
\hline
\end{tabular}

$\mathrm{NO}_{3}-\mathrm{N}($ Sig. $<0.01)$ and DO (Sig. < 0.05) are correlated to spatial variations through SCA. Relatively fewer parameters in spatial SCA indicate that there is lack of dissimilarity in spatial scale; all the three river-courses may have a similar pollution condition. According to the results from SCA and DA, TN and Chl- $a$ can be determined by DA but not SCA, which means the variation of these two parameters only exist in specific parts of the river course. DO is significant in SCA but not in SCA, and loss of discriminant ability may contribute to the unset distribution of pollutants, which are caused by point source pollution.

Box and whisker plots of the selected parameters of spatial trends are illustrated in Figure 4. From the point of variation amplitude, $\mathrm{NO}_{3}-\mathrm{N}$ varies between 1.33 and $15.18 \mathrm{mg} / \mathrm{L}$ at upstream, 4.62-12.30 mg/L at middle-stream, and 1.20-9.65 mg/L at downstream, the great variation means an uneven distribution in different parts of the river course.TN has the greatest variation at up-stream. For Chl- $a$, the greatest variation appears at down-stream. From comparison between average values in the three parts of the river course, $\mathrm{NO}_{3}-\mathrm{N}$ does not show a dramatic variation, as well as $\mathrm{TN}$ and Chl- $a$, which further explains the low accuracy in spatial DA. As the main sewage drainage river course, TSBR is largely affected by domestic wastewater. Automatically, the high $\mathrm{NO}_{3}-\mathrm{N}$, which is the degradative product of nitrogen organic matter by microbial action, is mainly from domestic wastewater [43]. Besides, TN, Chl- $a$ are infected by the fact that factories along the river course do not have obvious geographical characteristics or discharge frequency. 

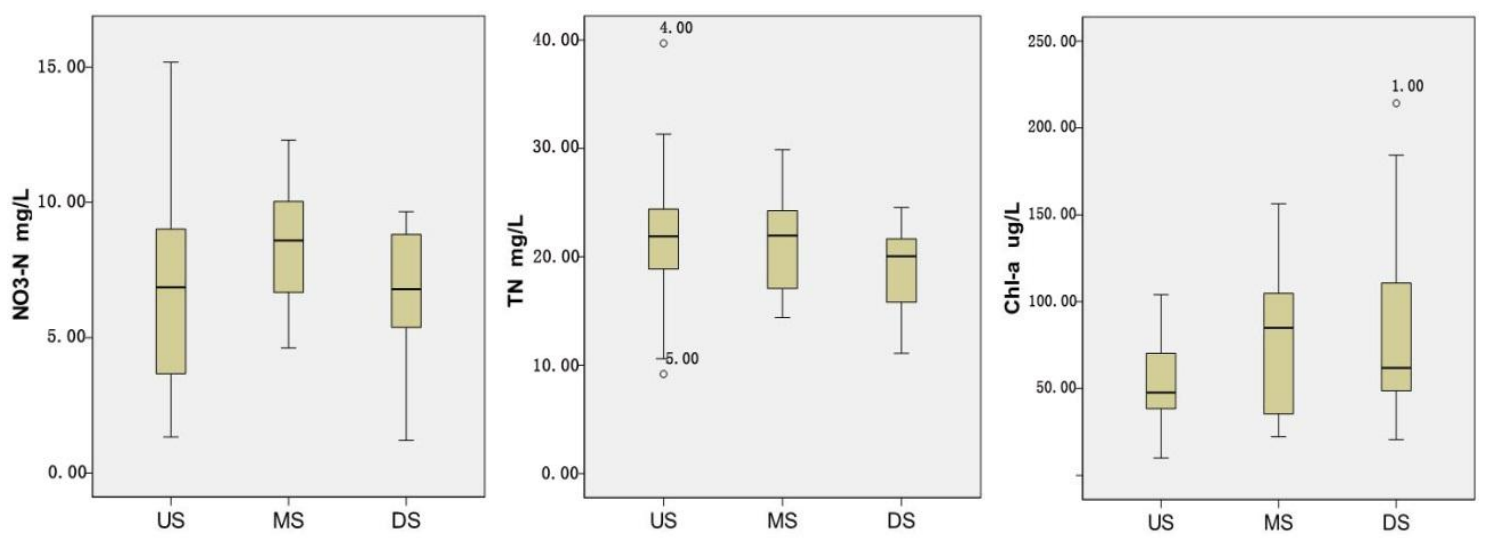

Figure 4. The trend of spatial variations of significant water quality parameters in TSBR.

\subsection{Source Identification}

PCA/FA is applied in recognizing main factors of water pollution. As pointed out in Section 3.2.2, temporal variation is greater than spatial variation, thus the paper focuses on recognizing pollution factors in different periods, as delineated by HCA. Eigenvalues greater than one are taken as the criterion for extraction of the factors required to explain the sources of variances in the data. Each extraction factor contains comprehensive information of the original variables, so it may be hard to explain. Therefore, a rotation must be made upon the extraction factors in order to make clear the meaning of each factor. In this paper, varimax rotation is adopted to minimize the variables with the highest load in each factor. The new group of variables is known as variance factors (VFs). Classification of factor loading is thus "strong", "moderate" and "weak", corresponding to absolute loading values of $>0.75,0.75-0.50$, and $0.50-0.30$, respectively [44]. Corresponding VFs, variables loading and variance in two periods are presented in Table 7; strong and moderate loading values have been highlighted by underline and bold.

Table 7. Factor loadings value and explained variance of water quality parameters in two periods.

\begin{tabular}{ccccccc}
\hline \multirow{2}{*}{ Parameters } & \multicolumn{3}{c}{ Rapid-Flow Period } & \multicolumn{3}{c}{ Gentle-Flow Period } \\
\cline { 2 - 7 } & $\mathbf{V F 1}$ & $\mathbf{V F 2}$ & $\mathbf{V F 3}$ & $\mathbf{V F 1}$ & VF2 & VF3 \\
\hline $\mathrm{NH}_{4}-\mathrm{N}$ & 0.169 & -0.092 & $\underline{0.913}$ & $\mathbf{0 . 6 5 4}$ & -0.022 & -0.593 \\
$\mathrm{NO}_{3}-\mathrm{N}$ & 0.368 & -0.108 & $\underline{-0.868}$ & $\underline{-0.886}$ & -0.409 & 0.139 \\
$\mathrm{TN}$ & $\mathbf{0 . 6 2 3}$ & -0.033 & -0.317 & 0.050 & $\underline{-0.868}$ & 0.030 \\
$\mathrm{TP}$ & $\underline{0.924}$ & -0.072 & 0.101 & -0.027 & 0.170 & $\underline{0.769}$ \\
$\mathrm{PO}_{4}-\mathrm{P}$ & $\underline{\mathbf{0 . 7 9 7}}$ & 0.177 & -0.186 & 0.099 & -0.053 & $\underline{0.871}$ \\
$\mathrm{COD}$ & $\mathbf{0 . 6 0 7}$ & 0.334 & 0.278 & $\underline{0.854}$ & -0.141 & 0.393 \\
$\mathrm{BOD}$ & 0.101 & $\underline{0.848}$ & 0.046 & $\underline{0.921}$ & -0.159 & -0.065 \\
$\mathrm{Chl}-\boldsymbol{a}$ & 0.172 & $\underline{0.860}$ & -0.068 & -0.072 & $\underline{0.858}$ & -0.110 \\
$\mathrm{SS}$ & $\mathbf{0 . 7 0 0}$ & 0.108 & 0.189 & 0.368 & 0.325 & -0.424 \\
$\mathrm{DO}$ & -0.435 & $\mathbf{0 . 7 4 9}$ & 0.031 & 0.127 & $\underline{0.787}$ & 0.278 \\
\hline Eigenvalue & 3.13 & 2.20 & 1.85 & 2.96 & 2.46 & 2.15 \\
Variance \% & 31.30 & 22.01 & 18.51 & 29.59 & 24.58 & 21.50 \\
Cumulative variance\% & 31.30 & 53.31 & 71.82 & 29.59 & 54.17 & 75.67 \\
\hline
\end{tabular}

For the dataset from the rapid-flow period, three VFs accounts for $71.82 \%$ of total variance. VF1 explaining $31.30 \%$ of total variance, which has strong positive loadings on $\mathrm{TP}, \mathrm{PO}_{4}-\mathrm{P}, \mathrm{SS}, \mathrm{TN}$ and COD. Phosphorus indicators imply that part of this pollution is from sewage discharge; on the other hand, organic pollutants have been intensely decreasing in supplementary (reclaimed water from treatment plants); a positive correlation of organic pollutant (COD and SS) means that these are mainly from non-point source pollution like agricultural runoff and atmospheric sedimentation but not from sewage discharges. Thus, VF1 represents a combination of point source and non-point 
source pollution [38]. VF2, explaining $22.01 \%$ of total variance, has positive loading on $\mathrm{BOD}_{5}, \mathrm{Chl}_{-} a$ and DO, which can be interpreted as bio-chemical pollution and eutrophication caused by sewage discharge [6,10]. VF3, explaining $18.51 \%$ of total variance, has a positive loading on $\mathrm{NH}_{4}-\mathrm{N}$ and negative loading on $\mathrm{NO}_{3}-\mathrm{N}$. Nitrification in the water body is the main reason for $\mathrm{NO}_{3}-\mathrm{N}$ decrease and $\mathrm{NH}_{4}-\mathrm{N}$ increase [45]. Thus, VF3 represent nitrogen pollution caused by rainfall and surface runoff.

Three VFs accounts for $75.67 \%$ of total variance in the gentle-flow period. Among the three VFs, VF1 explains $29.59 \%$ of total variance, has strong positive loadings on $\mathrm{BOD}_{5}, \mathrm{COD}, \mathrm{NH}_{4}-\mathrm{N}$, and negative loading on $\mathrm{NO}_{3}-\mathrm{N}$. As for local field situations, VF1 basically represent domestic and industrial sewage. VF2, explaining $24.58 \%$ of total variance, has positive loadings on Chl- $a$, DO and negative loading on $\mathrm{NO}_{3}-\mathrm{N}$. Previous studies show that microbial activities can increase denitrification and consume the inorganic nitrogen in water [46-48]. Therefore, VF3 can be interpreted as the effects of algae and other aquatic plants. VF3 has positive loadings on $\mathrm{TP}$ and $\mathrm{PO}_{4}-\mathrm{P}$, both of which can be regarded as phosphorus pollution caused by domestic discharge.

In summary, for an urban river course, the constitution of pollutants differs from natural water bodies, but both of them are obviously disturbed by human activities. Point-source pollution, like domestic sewage and industrial wastewater, is the main pollution source of both urban and natural river water bodies, which is consistent with previous research [34,49-51].

\section{Conclusions and Discussions}

As a significant part of an urban ecosystem, an urban river course plays an important role in carrying municipal industrial wastewater and agricultural runoff [52]. Research on urban river water-quality status as well as pollution distribution may serve as important guidance for urban water environment improvement.

This paper reveals that water environment has been seriously degrading in TSBR influenced by both internal and external source pollution. Most of the monitoring parameters are far beyond the national standard V. N and P are the most severe ones, while Chl- $a$, DO make up the uneven distribution ones. This indicates that water eutrophication is serious and the self-cleaning ability of the water is poor in the study area. With the gradual decrease of rainfall and the increase of wastewater discharge in recent years, and the rapid development of urbanization, this has led to an increase in sewage discharge of the Beiyun River. In addition, due to the drought in successive years, the amount of clear water resources is insufficient and the proportion of sewage is increasing, resulting in a decrease in the dilution and natural purification of rivers. The external reason is that the Tongzhou section of the Beiyun River is a gate-controlled river, and the river channel is silted. The water flow is relatively small, which leads to the reduction of the water's self-purification capacity. The deterioration of water quality in the urban river course of the Beiyun River is greatly affected by the inflow of sewage into the river. The interception of sewage is a prerequisite for the improvement of the water quality of the Tongzhou section of the Beiyun River in the future.

In this paper, HCA is applied to the river water quality, and the whole data set can be divided into two parts: rapid-flow period (May-October), and gentle-flow period (March-April). From the dendrogram in Figure 2a, it can be seen that May is included in dry season along with March and April, but the month also shows similar characteristics with wet seasons like June and August. This means precipitation is not the key factor resulting in the change of pollution condition in the urban river course; sewage discharge is the dominant factor of the seasonal distribution of water quality. Therefore, it can be concluded that highly artificialization characteristics have resulted in the changes of nature feature of the urban river course. The urban river course suffers from point and non-point source pollution at the same time, presenting a far more serious water condition. For different periods, water pollution in the rapid-flow period is more severe than the gentle-flow period as interpreted by FCA, which means the infusion of runoffs during the rapid-flow period does not dilute the pollutant concentration within water body. On the contrary, the infusion of runoff becomes the secondary pollution source. As stepwise mode assigns 93.3\% of cases correctly, three parameters (Chl- $a$, TN, 
$\left.\mathrm{PO}_{4}-\mathrm{P}\right)$ demonstrated their good performance in explaining temporal variation of water quality successfully; in monitoring the frequency of these three parameters should be appropriately increased in future works. The results of SCA and DA comprehensively suggest that $\mathrm{NH}_{4}-\mathrm{N}, \mathrm{TP}, \mathrm{BOD}_{5}$ are highly vulnerable to human activities.

TSBR is the typical river course protection built by laying bricks or stones which are carried out on both sides of the river bank and its bottom; this highly artificialized action leads to a great variation for hydrochemical and hydrological characteristics compared to a natural river course. Because of the limited catchment area compared to natural rivers, the paper fails to find a dramatic spatial variation of water quality in different reaches. Thus, the paper only focuses on pollution identification in different periods. The results show that influences by multivariate factors like precipitation, temperature, sources/constituents are different between the two periods. During the rapid-flow period, water is polluted by a combination of organic matter (non-point source pollutant) and phosphorus (point source pollutant), bio-chemical pollutants and nitrogen (point source pollutant). For the gentle-flow period, water quality is influenced by domestic and industrial waste (point source pollutant), the activities of algae and aquatic plants, and phosphorus pollution (point source pollutant). Point-source pollution is blamed for water deterioration in both periods. Due to a lack of precipitation and runoff, agricultural runoff is no longer responsible for water deteriorating during the gentle-flow period. Thus, future works should focus on the restraint of domestic and industrial releases for the gentle-flow period, while during the rapid-flow period, various protection measures should be put into effect for reducing non-point source pollution.

Strategies on storm water management have been explored and put into practice in some areas around the world, but there is still increasing concern about how to better utilize storm water in the future, especially for countries that lack water resources. Furthermore, some techniques should be adopted, such as the increase of impervious area and the application of low-impact development or integrated management practices, in managing storm water runoff in the future.

Author Contributions: J.R., J.L., and X.Z. conceived and designed the research theme. B.R. collected the data and designed the methods. J.R., J.L., X.Z., and C.G. analyzed the data and interpreted the results. J.R. wrote and edited the paper.

Funding: This research was funded by the Government Financial Grants Project (ZNGZ2015-036) and the APC was funded by the Government Financial Grants Project (ZNGZ2015-036).

Acknowledgments: This research was supported by the Government Financial Grants Project (ZNGZ2015-036). We thank the editors of the journal and the reviewers for their useful comments and suggestions for improvements.

Conflicts of Interest: The authors declare no conflict of interest.

\section{References}

1. Costanza, R.; D'Arge, R.; De, G.R. The value of the world's ecosystem services and natural capital. Nature 1997, 387, 253-260. [CrossRef]

2. Singh, K.P.; Malik, A.; Mohan, D. Multivariate statistical techniques for the evaluation of spatial and temporal variations in water quality of Gomti River (India): A case study. Water Res. 2004, 38, 3980-3992. [CrossRef] [PubMed]

3. Vega, M.; Pardo, R.; Barrado, E. Assessment of seasonal and polluting effects on the quality of river water by exploratory data analysis. Water Res. 1998, 32, 3581-3592. [CrossRef]

4. Qiu, J.L.; Shen, J.Y.; Wei, G.Y.; Wang, G.B.; Xie, H.; Lv, G.P. A systematic assessment of watershed-scale nonpoint source pollution during rainfall-runoff in the Miyun Reservoir watershed. Environ. Sci. Pollut. Res. 2018, 25, 6514-6531. [CrossRef] [PubMed]

5. Shen, J.Y.; Qiu, J.L.; Hong, Q.; Chen, L. Simulation of spatial and temporal distributions of non-point source pollution load in the Three Gorges Reservoir Region. Sci. Total Environ. 2014, 493, 138-146. [CrossRef] [PubMed]

6. Simeonov, V.; Stratis, J.A.; Samara, C. Assessment of the surface water quality in Northern Greece. Water Res. 2003, 37, 4119-4124. [CrossRef] 
7. Soko, M.I.; Gyedu-Ababio, T. The spatial and temporal variations of Ichythyofauna and water quality in the Crocodile River (East), Mpumalanga, South Africa. J. Water Res. Prot. 2015, 7, 152-170. [CrossRef]

8. Gert-Jan, W.; Mathias, B.; La, T.N.; Zita, S.; Fabrice, G.R. Spatial and temporal variability of surface water pollution in the Mekong Delta, Vietnam. Sci. Total Environ. 2014, 485-486, 653-665.

9. Mei, K.; Liao, L.L.; Zhu, Y.L.; Lu, P.; Wang, Z.F.; Dahlgren, R.A.; Zhang, M.H. Evaluation of spatial-temporal variations and trends in surface water quality across a rural-suburban-urban interface. Environ. Sci. Pollut. Res. 2014, 21, 8036-8051. [CrossRef] [PubMed]

10. Zhou, F.; Hao, Z.J.; Guo, H.C. Temporal and spatial distribution patterns of marine water quality in Eastern Hong Kong. Acta Sci. Circumst. 2007, 27, 1517-1524. (In Chinese)

11. Pejman, A.H.; Bidhendi, G.; Karbassi, A. Evaluation of spatial and seasonal variations in surface water quality using multivariate statistical techniques. Int. J. Environ. Sci. Technol. 2009, 6, 467-476. [CrossRef]

12. Sharma, M.; Kansal, A.; Jain, S.; Sharma, P. Application of multivariate statistical techniques in determining the spatial temporal water quality variation of Ganga and Yamuna Rivers present in Uttarakhand State, India. Water Qual. Expo. Health 2015, 7, 567-581. [CrossRef]

13. Koklu, R.; Sengorur, B.; Topal, B. Water quality assessment using multivariate statistical methods-A case study: Melen River System (Turkey). Water Resour. Manag. 2010, 24, 959-978. [CrossRef]

14. Adebola, A.O.; Seun, M.A.; Oladele, O. Water quality assessment of river Ogun using multivariate statistical techniques. J. Environ. Prot. 2013, 4, 466-479.

15. Islam, M.M.; Lenz, O.K.; Azad, A.K.; Ara, M.H.; Rahman, M.; Hassan, N. Assessment of spatio-temporal variations in water quality of Shailmari River, Khulna (Bangladesh) using multivariate statistical techniques. J. Geosci. Environ. Prot. 2017, 5, 1-26. [CrossRef]

16. Wu, Y.M.; Chen, Q.W.; Li, J. Fuzzy comprehensive assessment on spatio-temporal variations of water quality of a small catchment. Acta Sci. Circumst. 2011, 31, 1198-1205. (In Chinese)

17. Lu, R.S.; Lo, S.L. Diagnosing reservoir water quality using self-organizing maps and fuzzy theory. Water Res. 2002, 36, 2265-2274. [CrossRef]

18. Yu, Y.X.; Liao, H.K.; Zhou, Y.; Zhong, W. Reasoning and fuzzy comprehensive assessment methods based CAD system for boiler intelligent design. J. Mech. Sci. Technol. 2015, 3, 1123-1130. [CrossRef]

19. Zhou, F.; Liu, Y.; Guo, H. Application of multivariate statistical methods to water quality assessment of the watercourses in Northwestern New Territories, Hong Kong. Environ. Monit. Assess. 2007, 132, 1-13. [CrossRef] [PubMed]

20. Tabata, T.; Hiramatsu, K.; Harada, M. Assessment of the water quality in the Ariake Sea using principal component analysis. J. Water Res. Prot. 2015, 1, 41-49. [CrossRef]

21. Mohammad, H.; Assefa, M.M. Assortment and spatiotemporal analysis of surface water quality using cluster and discriminant analyses. CATENA 2017, 247-258.

22. Reghunath, R.; Murthy, T.R.; Raghavan, B.R. The utility of multivariate statistical techniques in hydrogeochemical studies: An example from Karnataka, India. Water Res. 2002, 36, 2437-2442. [CrossRef]

23. Emad, A.M.S.; Ahmed, M.T.; Eethar, M.A.O. Assessment of water quality of Euphrates River using cluster analysis. J. Environ. Prot. 2012, 12, 1629-1633.

24. Alberto, W.D.; Marýìa, D.P.D.; Marýìa, V.A. Pattern recognition techniques for the evaluation of spatial and temporal variations in water quality. A case study: Suquýìa River Basin (Córdoba-Argentina). Water Res. 2001, 35, 2881-2894. [CrossRef]

25. Onkal-Engin, G.; Demir, I.; Hiz, H. Assessment of urban air quality using fuzzy synthetic evaluation. Atmos. Environ. 2004, 38, 3809-3815. [CrossRef]

26. Lao, S. Fuzzy comprehensive assessment of urban overall environmental quality. China Environ. Sci. 1990, 10, 93-97.

27. Wang, P. Fuzzy Sets and Their Application; Shanghai Science and Technology Press: Shanghai, China, 1983. (In Chinese)

28. Wang, H.Y. Assessment and prediction of overall environmental quality of Zhuzhou City, Hunan Province, China. J. Environ. Manag. 2002, 66, 329-340.

29. Zhou, F.; Guo, H.C.; Liu, Y. A new approach for water quality assessment based on multivariate statistical analysis and Radial Basis Function Neural Networks. Acta Sci. Circumst. 2007, 27, 846-853. (In Chinese)

30. Lattin, J.M.; Carroll, J.D.; Green, P.E. Analyzing Multivariate Data; Thomson Brooks/Cole: Pacific Grove, CA, USA, 2003. 
31. Tabachnick, B.G.; Fidell, L.S. Using Multivariate Statistics, 3rd ed.; Harper Collins College Publishers: New York, NY, USA, 1996.

32. Shrestha, S.; Kazama, F. Assessment of surface water quality using multivariate statistical techniques: A case study of the Fuji river basin, Japan. Environ. Model. Softw. 2007, 22, 464-475. [CrossRef]

33. Pekey, H.; Karaka, D.; Bakoglu, M. Source apportionment of trace metals in surface waters of a polluted stream using multivariate statistical analysis. Mar. Pollut. Bull. 2004, 49, 809-818. [CrossRef] [PubMed]

34. Suthar, S.; Sharma, J.; Chabukdhara, M. Water quality assessment of river Hindon at Ghaziabad, India: Impact of industrial and urban wastewater. Environ. Monit. Assess. 2010, 165, 103-112. [CrossRef] [PubMed]

35. Alam, J.B.; Hossain, A.; Khan, S.K. Deterioration of water quality of Surma River. Environ. Monit. Assess. 2007, 134, 233-242. [CrossRef] [PubMed]

36. Trauth, R.; Xanthopoulos, C. Non-point pollution of groundwater in urban areas. Water Res. 1997, 31, 2711-2718. [CrossRef]

37. Evans, D.J.; Johnes, P.J.; Lawrence, D.S. Physico-chemical controls on phosphorus cycling in two lowland streams. Part 2-the sediment phase. Sci. Total Environ. 2004, 329, 165-182. [CrossRef] [PubMed]

38. Eganhouse, R.P.; Sherblom, P.M. Anthropogenic organic contaminants in the effluent of a combined sewer overflow: Impact on Boston Harbor. Mar. Environ. Res. 2001, 51, 51-74. [CrossRef]

39. Fernandez, H.M.; Conti, L.F.C.; Patchineelam, S.R. An assessment of the pollution of heavy metals in Jacarepagua basin, Rio de Janeiro, Brazil: A statistical approach. Environ. Technol. 1994, 15, 87-94. [CrossRef]

40. Sui, S.F.; Luo, Q.F. Release Character of Phosphorus from the Sediments of East Lake, Wuhan. Environ. Sci. 2001, 22, 102-105. (In Chinese)

41. Kannel, P.R.; Lee, S.; Lee, Y.S. Assessment of spatial-temporal patterns of surface and ground water qualities and factors influencing management strategy of groundwater system in an urban river corridor of Nepal. J. Environ. Manag. 2008, 86, 595-604. [CrossRef] [PubMed]

42. Ho, M.H.; Huang, J.L. Identification of spatio-temporal variation in the seaside water quality along Macau Peninsula. Environ. Sci. 2010, 31, 606-611. (In Chinese)

43. Xi, D.L.; Sun, Y.S.; Liu, X.Y. Environmental Monitoring; Higher Education Press: Beijing, China, 1999. (In Chinese)

44. Liu, C.W.; Lin, K.H.; Kuo, Y.M. Application of factor analysis in the assessment of groundwater quality in a blackfoot disease area in Taiwan. Sci. Total Environ. 2003, 313, 77-89. [CrossRef]

45. Iscen, C.F.; Emiroglu, Ö.; Ilhan, S. Application of multivariate statistical techniques in the assessment of surface water quality in Uluabat Lake, Turkey. Environ. Monit. Assess. 2008, 144, 269-276. [CrossRef] [PubMed]

46. Xing, G.; Cao, Y.; Shi, S. N pollution sources and denitrification in waterbodies in Taihu Lake region. Sci. China Ser. B Chem. 2001, 44, 304-314. (In Chinese) [CrossRef]

47. Andersen, T.K.; Jensen, M.H.; Sørensen, J. Diurnal variation of nitrogen cycling in coastal, marine sediments. Mar. Biol. 1984, 83, 171-176. [CrossRef]

48. Andersen, J.M. Significance of denitrification on the strategy for preserving lakes and coastal areas against eutrophication. In Denitrification in the Nitrogen Cycle; Plenun Press Publishing Corporation: New York, NY, USA, 1985; pp. 171-190.

49. Wang, C.Y.; Yang, Y.H.; Zhou, F. Spatio-temporal characteristics and source identification of water pollutants in River Qinhe Basin. Acta Sci. Circumst. 2012, 32, 2267-2278. (In Chinese)

50. Ouyang, Y.; Nkedi-Kizza, P.; Wu, Q.T. Assessment of seasonal variations in surface water quality. Water Res. 2006, 40, 3800. [CrossRef] [PubMed]

51. Chen, P.; Li, L.; Zhang, H.B. Spatio-temporal variations and source apportionment of water pollution in Danjiangkou Reservoir Basin, Central China. Water 2015, 7, 2591-2611. [CrossRef]

52. Panda, U.C.; Sundaray, S.K.; Rath, P. Application of factor and cluster analysis for characterization of river and estuarine water systems-A case study: Mahanadi River (India). J. Hydrol. 2006, 331, 434-445. [CrossRef]

(C) 2018 by the authors. Licensee MDPI, Basel, Switzerland. This article is an open access article distributed under the terms and conditions of the Creative Commons Attribution (CC BY) license (http://creativecommons.org/licenses/by/4.0/). 